\title{
Luteolin inhibits cell proliferation and induces cell apoptosis via down-regulation of mitochondrial membrane potential in esophageal carcinoma cells EC1 and KYSE450
}

\author{
Ping Chen ${ }^{1,2}$, Jing-Yang Zhang ${ }^{1,2}$, Bei-Bei Sha ${ }^{1,2}$, Yan-Er Ma ${ }^{1,2}$, Tao $\mathrm{Hu}^{1,2}$, Yang-Cheng \\ $\mathrm{Ma}^{1,2}$, Hao Sun ${ }^{3}$, Jian-Xiang Shi', Zi-Ming Dong ${ }^{1,2}$, Pei Li ${ }^{1,2}$ \\ ${ }^{1}$ Cancer Chemoprevention Collaborative Innovation Center in Henan Province, Zhengzhou University, Zhengzhou, Henan, \\ 450001, China \\ ${ }^{2}$ Department of Pathophysiology, College of Basic Medical Sciences, Zhengzhou University, Zhengzhou, Henan, 450001, China \\ ${ }^{3}$ College of Public Health, Henan Key Laboratory for Tumor Epidemiology, Affiliated Tumor Hospital, Zhengzhou University, \\ Zhengzhou, Henan, 450001, China \\ Correspondence to: Pei Li, email: lipeifreemai@zzu.edu.cn \\ Zi-Ming Dong, email: Dongzm@zzu.edu.cn \\ Jian-Xiang Shi, email: jianxiangshi@zzu.edu.cn \\ Keywords: Iuteolin, esophageal squamous carcinoma, cell proliferation, mitochondrial membrane potential, chemotherapy \\ Received: September 02, $2016 \quad$ Accepted: February 06, $2017 \quad$ Published: March 02, 2017 \\ Copyright: Chen et al. This is an open-access article distributed under the terms of the Creative Commons Attribution License \\ (CC-BY), which permits unrestricted use, distribution, and reproduction in any medium, provided the original author and source \\ are credited
}

\section{ABSTRACT}

In current study, we investigated the anti-tumor effect of luteolin in human ESCC cell lines in vitro and in vivo and tried to explore the potential mechanisms. Results from flow cytometry showed that luteolin could induce apoptosis and caspase-3 activation and induce cell cycle arrest at G2/M phase in a dose- and time-dependent manner in EC1 and KYSE450 cells. JC-1 test results showed that membrane potential of mitochondria after luteolin treatment was down-regulated and this was an indicator for intrinsic apoptosis. Western Blot results showed the expression of cell cycle regulatory protein p21 and p53 increased and three apoptosis related proteins that participate in mitochondrial apoptotic pathway, namely, Bim, CYT-c and cPARP, also increased in luteolin treated cells compared with control groups. We further confirmed that luteolin could significantly inhibit the growth of ESCC tumors in xenograft mouse models and no evidence of systemic toxicity was observed. Our results suggest that luteolin can induce cell apoptosis and cell cycle arrest in G2/M phase through mitochondrial pathway in EC1 and KYSE450 cell lines and proper utilization of luteolin might be a practical approach in ESCC chemotherapy.

\section{INTRODUCTION}

Esophageal squamous cell carcinoma (ESCC), the predominant histological subtype of esophageal cancer, and it is characterized by high mortality and striking geographic variation throughout the world with the highest incidence rate in east Asia [1, 2]. ESCC is characterized with high metastatic rate, high mortality rate and poor prognosis. Generally, the 5-year survival rate for esophageal cancer that localized only in esophagus is $40 \%$ while the rate for esophageal cancer with distant metastasis is only $4 \%$, and the overall 5-year survival rate for esophageal cancer is less than 20\% [3]. Most ESCC patients present with advanced metastatic disease because people tend to seek for medical assistance after symptoms develop [4]. Currently, surgical resection is curative only at an early stage in ESCC and chemoradiotherapy is recommended for majority of patients with advanced esophageal cancer [5-7]. Traditional chemotherapy drugs, such as cisplatin, carboplatin, have certain effects on ESCC, at the same time the regimen have a high incidence of side effects, such as mucositis and leukocytopenia, as well as treatment-related death $(16 \%)$ [8]. It is important to find chemotherapeutic agents with higher specificity, efficacy and fewer side effects for ESCC. 
Luteolin is a kind of natural plant flavonoid, which can be derived from a variety of vegetables, fruits, and medicinal herbs in glycosidic form [9]. Like other flavonoids, luteolin possesses many pharmacological properties including antioxidant, anti-tumor, antiinflammatory, cardio protective, and immune regulation $[10,11]$. Among these properties, anti-tumor activity has attracted more attention. Researchers have shown that luteolin has anti-tumor activities in several types of cancer cell lines, including apoptosis induction, cell cycle arrest, metastasis and angiogenesis inhibition in several different types of human cancer cell lines [12-14]. The anti-proliferation effect is associated with flavonoid induced cell cycle arrest, either at the G1/S or G2/M checkpoint [11, 15-19]. Many researchers have also tried to explored the underlying mechanisms [14, 20-23]. Zhang et al reported that luteolin can induce G2/M arrest in both KYSE510 ESCC and OE33 EAC cell lines [17, 18]. Wang et al reported that luteolin can induce G0/ G1 cell cycle arrest in Eca109 human ESCC cell line in vitro [19]. And these mechanisms might contribute to its anti-tumor effects. However, the anti-tumor activities in human esophageal cancers needs to be validated in vitro and in vivo.

Thus, we designed current study to focus on the cell cycle arrest and cell apoptotic effect of luteolin on esophageal cancer cells in vitro and try to explore the underlying mechanisms. Moreover, we investigated the anticancer potential of luteolin in vivo in ESCC xenograft mouse models.

\section{RESULTS}

\section{Luteolin inhibited proliferation and growth of EC1, EC9706, KYSE30 and KYSE450 cells in vitro}

As shown in Figure 1, the CCK-8 assay showed that luteolin could suppress the growth of these cells in a dose-dependent manner, compared to the control group (Figure 1A, 1B, 1C and 1D, both $p<0.05$ ). Considering the degree of differentiation and cell origins, we chose EC1 and KYSE450 cell lines in further experiments. The half maximal inhibitory concentration $\left(\mathrm{IC}_{50}\right)$ fell in 20 and $60 \mu \mathrm{M}$ range in these cell lines. We chose 20 and $40 \mu \mathrm{M}$ as experimental concentrations in further experiments to avoid severe cytotoxic side effect. Plate colony formation assay showed that different concentrations of luteolin could reduce the number of EC1 and KYSE450 cell colonies compared with control groups. Colony-forming efficacies of EC1 and KYSE450 cells were compromised with the increase of concentration of luteolin. Both colony numbers $(p<0.05)$ and in colony sizes decreased (Figure $1 \mathrm{E}, 1 \mathrm{~F}$ and $1 \mathrm{G})$. Moreover, morphological changes were also observed under the invert microscope in EC1 and KYSE450 cells after cells being treated with different concentrations of luteolin for $72 \mathrm{~h}$. Most of the cells had lost regular shape, cell junctions disappeared and cell adhesion decreased, cells could easily detach from the substrate after the plates were slightly shaken (Figure 1H). With the concentration of luteolin increased, floating dead cells and cell debris increased. No evidence of microbe or pathogen contamination was observed.
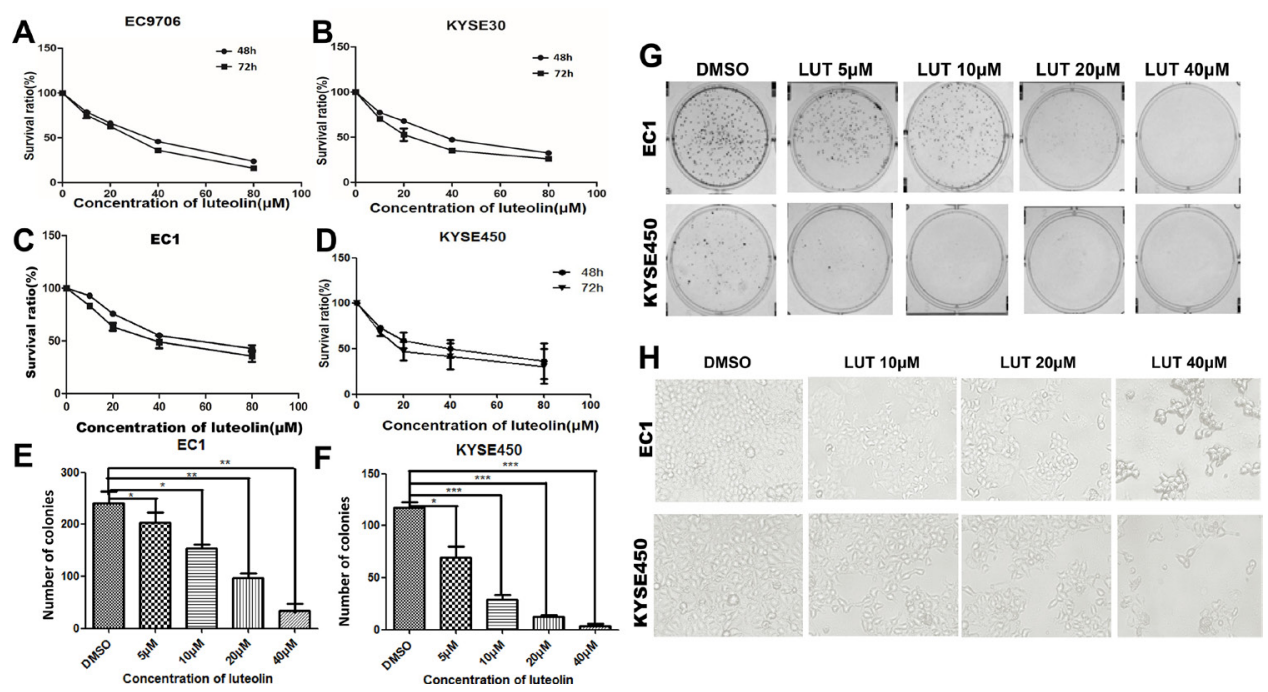

Figure 1: Luteolin inhibited cell proliferation and growth in ESCC cells. (A-D) Different ESCC cells were exposed to different concentrations of luteolin $(0,10,20,40,80 \mu \mathrm{M})$ for $48 \mathrm{~h}$ and $72 \mathrm{~h}$ and then cell viability was measured the by CCK-8 assay. (E) and (F) Colony count of EC1 and KYSE 450 cells after being treated with luteolin for $8 \mathrm{~d}$. Plate colony formation assay showed that luteolin could reduce the number of EC1 and KYSE450 cell colonies in a dose-dependent manner. (G) Representative images of cell colonies after being treated with different concentrations of luteolin for $8 \mathrm{~d}$. (H) Representative morphological changes under the invert microscope after EC1 and KYSE450 cells being treated with different concentrations of luteolin $(\times 200)$. The experiments were repeated three times. $\left({ }^{*} p<0.05,{ }^{* *} p<0.01\right)$. 
Luteolin induced cell cycle arrest with upregulation of the cell cycle inhibitory proteins p21 and p53 in ESCC cells

Several studies have demonstrated that luteolin could induce cell cycle arrest in different types of cancer cell lines, which can further lead to programmed cell death. The effect of luteolin on cell apoptosis was investigated by flow cytometry. The results show that luteolin induced cell growth inhibition EC1 and KYSE450 cells. Cell population increased in the G2/M phase but decreased in the $\mathrm{S}$ phase in a dosedependent manner both in EC1 and KYSE450 cells when compared with control group $(p<0.05$, Figure $2 \mathrm{~A}$ and 2B). Moreover, Western Blotting results show that with luteolin concentration increased, the expression of p21 and p53 proteins also increased (Figure 2C). Our data indicated that luteolin inhibited cell proliferation by blocking cells in G2/M phase and this process is associated with up-regulation of the cell cycle inhibitory proteins $\mathrm{p} 21$ and $\mathrm{p} 53$.

\section{Luteolin induced apoptosis via activating caspase-3 in EC1 and KYSE450 cells}

The effect of luteolin on cell apoptosis was further investigated by flow cytometry. The apoptotic rates at $72 \mathrm{~h}$ after different treatments are shown in Figure 3A. The total apoptotic rates (including early and late stages apoptotic rates) for EC1 and KYSE450 cells increased when compared with control groups (both $p<0.05$, Figure 3B). As shown in Figure $3 \mathrm{C}$ and $3 \mathrm{D}$, higher activity of caspase 3 in $\mathrm{EC} 1$ and KYSE450 cells was associated with higher luteolin concentrations (both $p<0.05$ ). These results indicated that luteolin could induce cell apoptosis via activating caspase-3.

\section{Luteolin could decrease mitochondrial membrane potential via up-regulation of Bim, CYT-C and CPARP protein}

JC-1 test results show that with luteolin concentration increased, mitochondrial membrane potential decreased ( $p<0.05$, Figure 4A, 4B). The

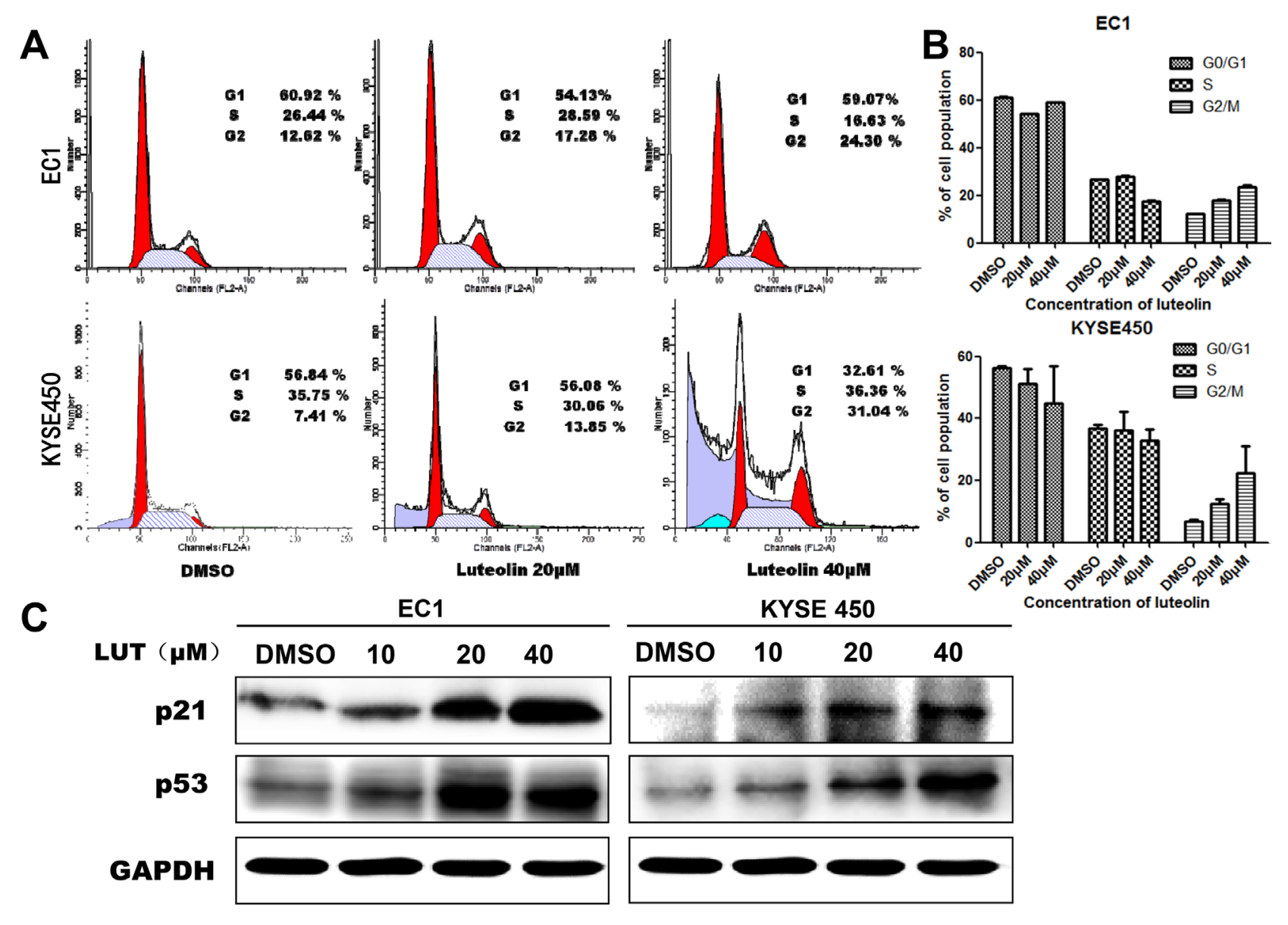

Figure 2: Luteolin induced the cell cycle arrest in EC1 and KYSE450 cells. (A) DNA contents were analyzed by flow cytometry after EC1 and KYSE450 cells being treated with different concentrations of luteolin $(0,20,40 \mu \mathrm{M})$ for $24 \mathrm{~h}$; (B) The percentage of cells in the $\mathrm{G} 0 / \mathrm{G} 1, \mathrm{~S}$, and G2/M phases of the cell cycle were calculated. Results are presented as mean \pm SD from three independent experiments. (C) Expression of p21 and p53 after EC1 and KYSE450 cells being treated with different concentrations of luteolin for $72 \mathrm{~h}$. GAPDH was used as reference. 

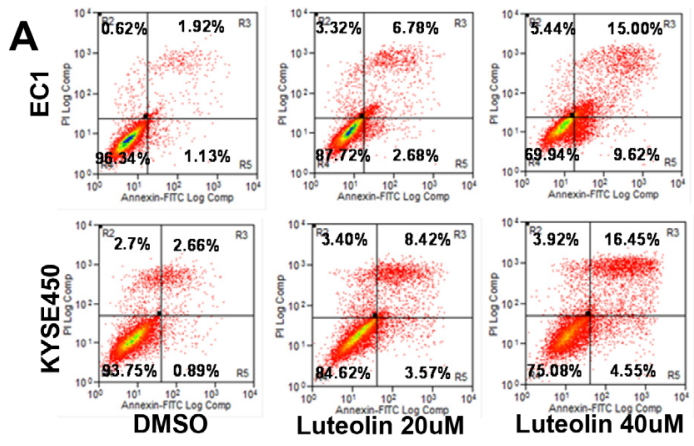

B
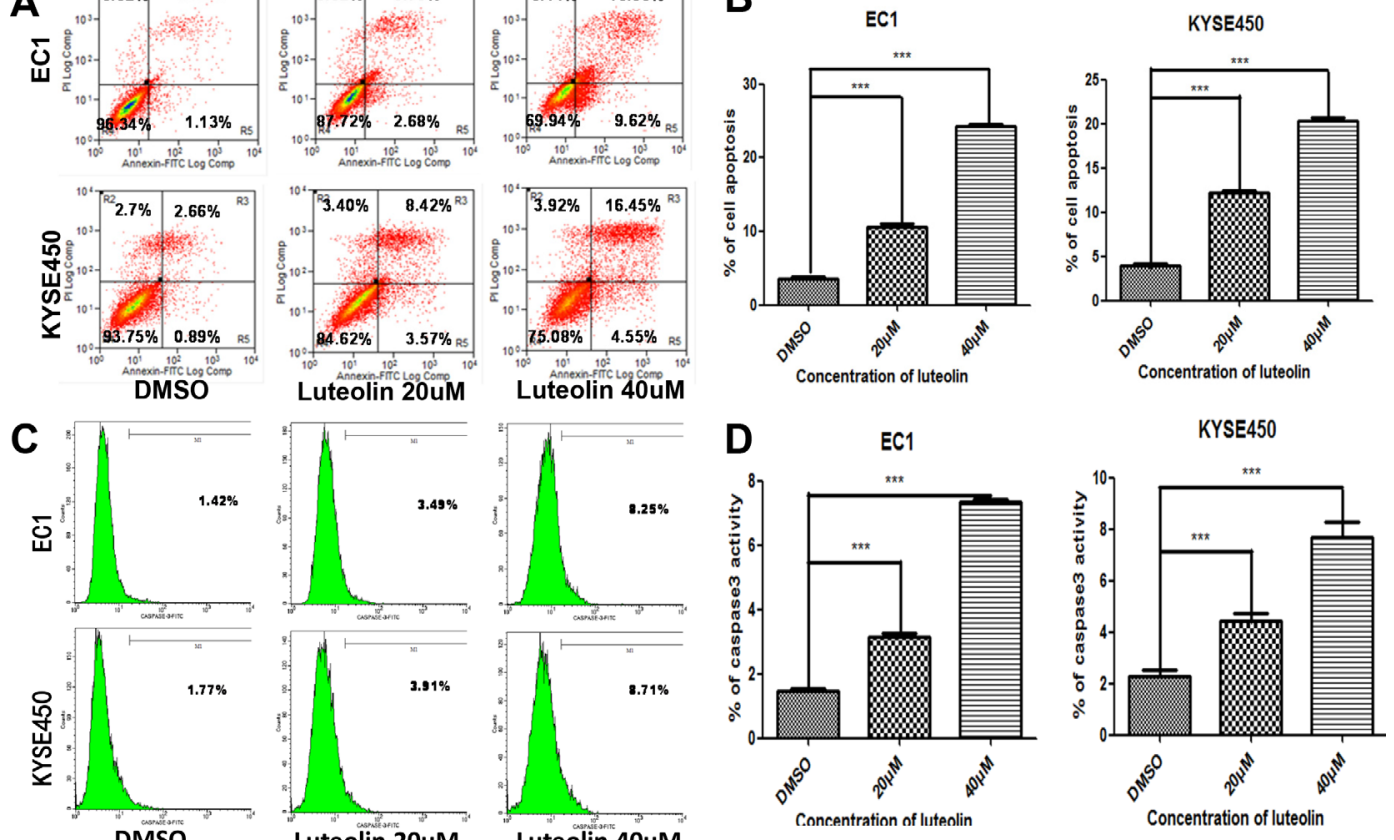

Figure 3: The effect of luteolin on cell apoptosis and caspase-3 activation were investigated by flow cytometry. (A) Apoptotic rate was analyzed by flow cytometry after EC1 and KYSE450 cells being treated with different concentrations of luteolin ( 0 , 20, $40 \mu \mathrm{M}$ ) for $72 \mathrm{~h}$. (B) The percentage of cell apoptosis after EC1 and KYSE450 cells being treated with different concentrations of luteolin were calculated. (C) and (D) Caspase-3 activation were investigated by flow cytometry. All results are expressed as mean \pm SD from three independent experiments. $(* * * p<0.001)$.
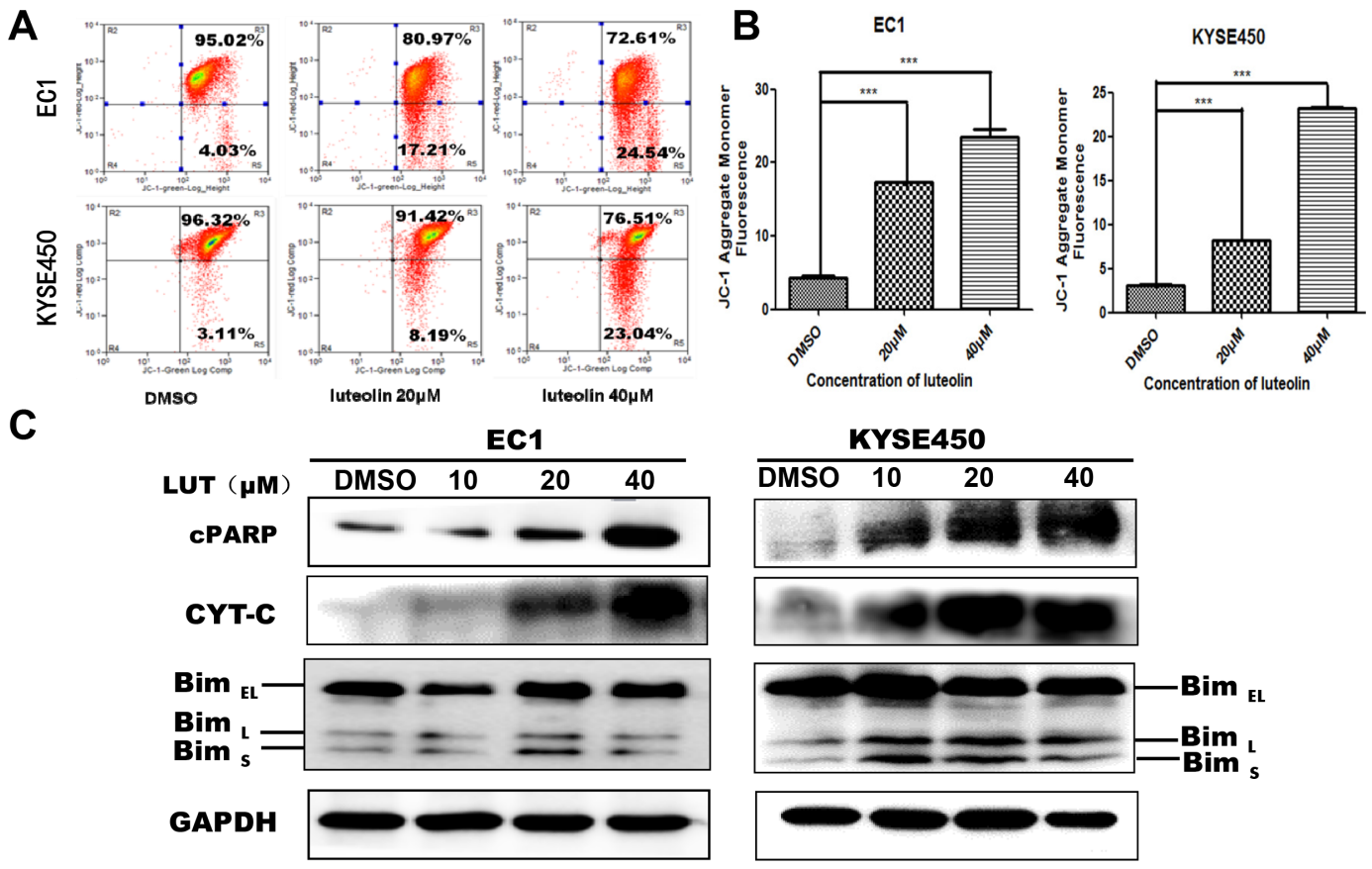

Figure 4: Mitochondrial membrane potential decreased and the expression mitochondrial apoptosis related proteins (cPARP, CYT-C, BimL and BimS) increased after being treated with luteolin. (A) Mitochondria membrane potential decreased after EC1 and KYSE450 cells being treated with luteolin in a dose-dependent manner. (B) Dose-dependent changes in mean JC-1 fluorescence after cells being treated with luteolin for $48 \mathrm{~h}$ (mean $\pm \mathrm{SD}$ from three independent experiments. *** $p<0.001)$. (C) Expression

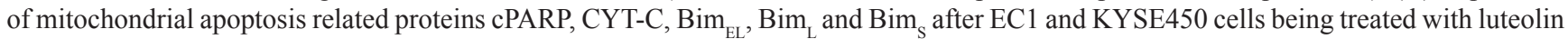
for $72 \mathrm{~h}$. GAPDH was used as reference. 
results indicate that luteolin induced EC1 and KYSE450 cells apoptosis through mitochondrial pathway. Western blotting assay further revealed that the expression of Bim, CYT-C and cPARP were positively associated with the concentrations of luteolin used in current study (Figure 4C). Considering the evidence provided here, we propose that luteolin might induce apoptosis in EC1 and KYSE450 cells through mitochondria-dependent apoptotic pathway.

\section{Luteolin inhibited esophageal tumor growth in xenograft mouse models}

Finally, we validated the anti-tumor effects of luteolin in EC1 mouse xenograft models. After subcutaneous injection of EC1-E-GFP cells, fourteen nude mice were randomly divided into two even groups: control group (DMSO) and luteolin treated group. The results showed that growth of EC1-EGFP tumors was significantly inhibited by administration of luteolin (Figure 5A). Tumor size decreased, total tumor weight reduced by about $65 \%$ in luteolin treated group compared with control group (Figure 5B, 5C). No evidence of systemic toxicity was observed in luteolin treated mice (Figure 5D). Evidences provided here indicate that luteolin can prevent tumor formation and progression in vivo.

\section{DISCUSSION}

Chemotherapy may be used to stall the development of ESCC and extend survival of ESCC patients [24, 25]. Cytotoxic agents, such as Cisplatin and Oxaliplatin, can be used as chemotherapeutic agents. However, cytotoxic chemotherapy is potentially hazardous because it may introduce side effects. In recent years, many researchers have paid attention to the utilization of natural extracts from plants as chemotherapeutic agents. Several studies have demonstrated that luteolin could induce cell cycle arrest and further inhibit proliferation and induce apoptosis in different types of cancer cells in vitro, including cell lines from hepatocellular carcinoma, cholangiocarcinoma, leukemia, thyroid cancer, breast cancer, prostate cancer, melanoma, lung cancer, oral squamous cancer, stomach cancer, gastric cancer, colon cancer, as well as ESCC and EAC [9, 17-19, 26-37].

In current study, we further confirmed the antiproliferation effect of luteolin in EC1 and KYSE450 ESCC cells. Results from CCK-8 assay showed that luteolin could suppress the growth of four ESCC cell lines in a dosedependent manner in vitro and compromise their colonyforming efficacies. This is consistent with findings from Zhang's and Wang's research groups [17-19]. In their studies, they reported that luteolin could induce growth inhibition in KYSE510 and Eca109 ESCC cell lines in a
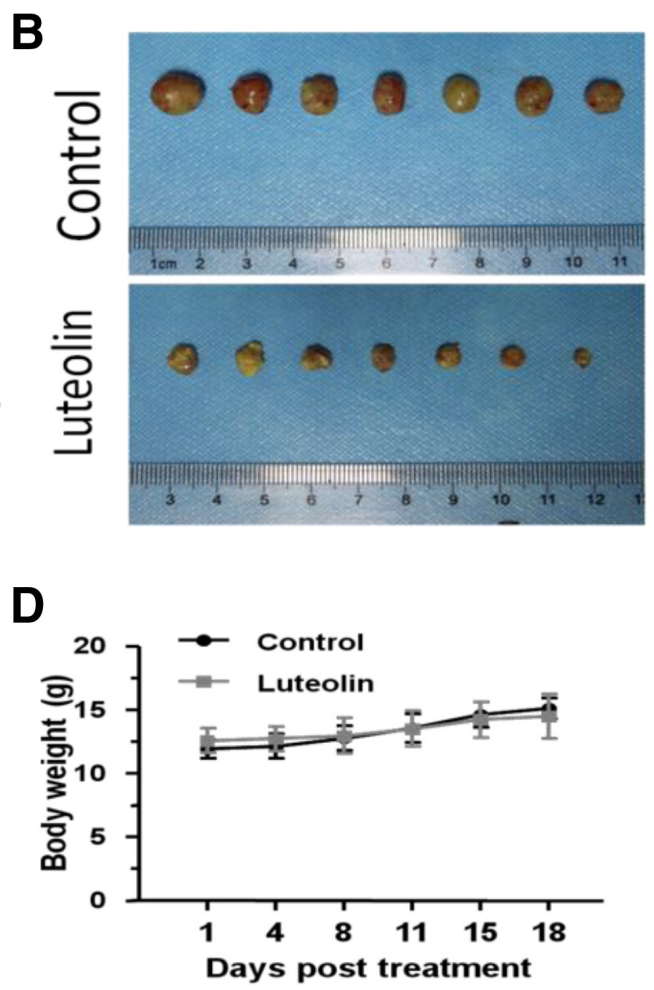

Figure 5: Luteolin inhibited tumor growth in ESCC xenograft mouse models. (A) Tumor size change in control and luteolin treated groups. (B) Tumors harvested in control and luteolin treated groups. (C) Tumor weight in control and luteolin treated groups. (D) Body weight change in control and luteolin treated groups. (mean $\pm \mathrm{SD},{ }^{*} p<0.05$ (Student's t-test). 
dose-dependent manner with estimated $\mathrm{IC}_{50}$ ranging from around 35 to $73 \mu \mathrm{M}[18,19]$. In current study, we have similar findings with the $\mathrm{IC}_{50}$ of luteolin falling in the range of 20 to $60 \mu \mathrm{M}$. $\mathrm{IC}_{50}$ varies in different cancer cell lines. This indicates that different cancer cell lines might have different sensitivity to luteolin induced cell cycle arrest. Considering results from $\mathrm{CCK}-8$ test and the degree of differentiation and origins of these four ESCC cell lines, EC1 and KYSE450 cells were chosen for further experiments. Results from flow cytometry revealed that EC1 and KYSE450 cells were arrested in G2/M phase after being treated with luteolin. Several studies have reported that luteolin can promote apoptosis but differentially induce cell cycle arrest in different types of cancer cell lines, either G1/S or G2/M arrest [9, 28-36, 38-40]. Given evidences provided here and by Zhang et al and Wang et al, it is postulated that luteolin can also differentially induce cell cycle arrest in different ESCC cell lines [18, 19].

In eukaryotes, two Cyclins (Cyclin A2 and Cyclin B1) and cyclin-dependent kinase 1 (CDK1) play central role in G2/M transition. P2 $1^{\mathrm{CIP} 1 / \mathrm{WAF} 1}$ is a kind of CDK inhibitors (CKIs), which can regulate the activities of CDKs [41]. In cell lines from breast cancer, colon cancer, prostate cancer and lung cancer, several researchers have reported that flavonoid could induce cell cycle arrest in G2/M phase via $\mathrm{p} 21^{\mathrm{CIP} 1 / \mathrm{WAF} 1}$ upregulation [18, 42-49]. In current study, we further confirmed this association. In addition, we also observed that p53 is overexpressed after luteolin treatment in both cell lines. Thus, we postulate that luteolin can induce cell cycle arrest in G2/M phase via upregulation of $\mathrm{p} 21^{\mathrm{CIP} 1}$ WAF1 and p53, and this can further induce apoptosis and inhibit cell proliferation in EC1 and KYSE450 cell lines.

There are two main pathways of apoptosis in mammals, intrinsic pathway, also called mitochondrial pathway, and extrinsic pathway. Mitochondrial pathway is the main target in developing anti-tumor drugs [50, 51]. P53, Bcl-2, Bax, caspase- 3 and PARP are important proteins that participate in cell apoptosis mediated by mitochondrial pathway. And release of cytochrome $\mathrm{C}$ (CYT-C) is a key event of cell apoptosis. Results from flow cytometry indicated that luteolin could increase apoptotic rate in both cancer cell lines and the activities of caspase-3 also significantly increased in a dose-dependent manner. Caspase- 3 plays a central role in the execution phase of cell apoptosis. Proteins from Bcl-2 family have an important role in the regulation of mitochondrial pathway and cytochrome $\mathrm{C}$ release. PARP can be inactivated by Caspase- 3 cleavage and this will activate programmed cell death. In current study, results from Annexin V/PI double stain apoptosis assay and caspase- 3 activities detection reveal that luteolin can induce apoptosis in EC1 and KYSE450 cells in a dosedependent manner and this is associated with increased caspase- 3 activities. Results from JC-1 kit assay revealed that membrane potential of mitochondrial decreased in a dose-dependent manner in these two cell lines after luteolin treatment. Results from Western Blot indicate that luteolin can upregulate $\mathrm{Bim}_{\mathrm{L}}$ and $\mathrm{Bim}_{\mathrm{S}}$ protein expression accompanied with CYT-C overexpression and cPARP cleavage. Based on these findings, we propose that luteolin can induce apoptosis in EC1 and KYSE450 cells through the mitochondrial pathway.

Furthermore, we constructed ESCC xenograft mouse models by subcutaneous injection of EC1-EGFP cells in nude mice. The results showed that tumor sizes in luteolin treated groups were significantly smaller than that in control groups. No significant cytotoxic side effects were observed since the body weight in both groups showed no difference. This is consistent with findings from other groups that luteolin can significantly inhibit cancer growth in vivo in xenograft mouse models for nonsmall cell lung cancer, squamous cell carcinoma of head and neck, breast cancer [37, 52-54].

In conclusion, current study has demonstrated that luteolin can induce cell cycle arrest in G2/M phase and apoptosis through mitochondrial pathway in EC1 and KYSE450 cell lines, and in vivo study has also demonstrated that luteolin can significantly inhibit the growth of tumor in ESCC xenograft mouse models. This has further elucidated the mechanisms of luteolin in ESCC treatment and prevention, and indicates that proper utilization of luteolin might be a practical approach in ESCC chemotherapy.

\section{MATERIALS AND METHODS}

\section{Ethics statement}

All experiments in present study were conducted in strict accordance with the recommendations in the Guide for the Care and Use of Laboratory Animals published by the US National Institutes of Health. The animal experiments were approved by the Animal Care and Use Committee at Zhengzhou University. The number of animals used was minimized, and all necessary precautions were taken to mitigate pain or suffering.

\section{In vitro experiment}

\section{Cell culture}

The human Esophageal squamous carcinoma cell lines (EC1, EC9706, KYSE30 and KYSE450) were purchased from Shanghai cell bank (China Academy of Science) and cultured in DMEM medium (KYSE450/KYSE30), RPMI 1640 (EC1/EC9706) (Thermo Fisher Scientific, Beijing, China) which were supplemented with $10 \%$ fetal bovine serum (FBS, Gibco BRL Life technologies, Rockville, MD, USA), $100 \mathrm{U} / \mathrm{ml}$ penicillin and $100 \mu \mathrm{g} / \mathrm{ml}$ streptomycin (Sigma, St. Louis, MO) respectively under a humidified atmosphere of $5 \% \mathrm{CO}_{2}$ at $37^{\circ} \mathrm{C}$. DMSO was used as drug delivery vehicle in all the in vitro experiments, and the final concentration of DMSO in negative control was $0.1 \%$. Cells were checked routinely and trypsinized until they reached $80-90 \%$ confluency. Luteolin was purchased from Enzo Life 
Sciences (Aladdin biological technology co. Ltd, Shanghai, China) and dissolved in DMSO solution prior to use.

\section{CCK-8 test}

The cell viability was examined via cell counting kit-8 (CCK-8 kit, Keygen biotech Co., Ltd, Nanjing, China) according to the manufacturer's instruction [55]. Briefly, approximately $3 \times 10^{3}$ cells were seeded in $100 \mu \mathrm{l}$ per well DMEM/RPMI 1640 in a 96-well plate. $100 \mu \mathrm{l}$ luteolin at concentrations of $0,10,20,40,80 \mu \mathrm{M}$ was added to the medium, and the cells were cultured for different time lengths ( $48 \mathrm{~h}$ and $72 \mathrm{~h}$ ). Subsequently, 10 $\mu \mathrm{l}$ of the CCK- 8 solution was added to each well and incubated at $37^{\circ} \mathrm{C}$ for another $2 \mathrm{~h}$. The absorbance at 450 $\mathrm{nm}$ was measured on a spectrophotometric plate reader. Each group was repeated in three different wells.

\section{Plate colony formation assay}

The ability of cells to form macroscopic colonies was determined by a plate colony formation assay [56]. Single cell suspensions derived from cells in the logarithmic phase were seeded in six-well plates (800/well), and luteolin at concentrations of $5,10,20$, and $40 \mu \mathrm{M}$ were used as treatment. After incubation at $37^{\circ} \mathrm{C}$ for $8 \mathrm{~d}$, colonies were rinsed with PBS, fixed with $4 \%$ paraformaldehyde at room temperature for $30 \mathrm{~min}$, and stained with $0.1 \%$ crystal violet (Sigma, St. Louis, MO, USA) for $30 \mathrm{~min}$. Only clearly visible colonies (foci $>50$ cells) were counted. The experiments were repeated three times.

\section{Flow cytometry for cell apoptosis and cell cycle distribution analysis}

The influence of luteolin on apoptosis and cell cycle distribution were detected with Annexin V-FITC-/PI apoptosis kit (Keygen biotech Co., Ltd, Nanjing, China) and cell cycle kit (Keygen biotech Co., Ltd, Nanjing, China) separately according to the manufacturer's instructions. KYSE450 and EC1 cells were exposed to luteolin at concentrations of 0,20 , and $40 \mu \mathrm{M}$ for $24 \mathrm{~h}$ or $72 \mathrm{~h}$. Then, cells were trypsinized, collected by centrifugation at $2000 \mathrm{rpm}$ for $5 \mathrm{~min}$ and washed with PBS. Then corresponding regents and solution were added and incubated according to manufacturer's instructions respectively. At the end of incubation, cell apoptosis distribution was analyzed on a flow cytometer (Becton Dickinson, USA), and cell cycle data was analyzed with ModFit software (Verity Software House, Topsham, ME).

\section{Flow cytometry for cell caspase-3 activity and mitochondrial membrane potential $(\Delta \Psi \mathrm{m})$ analysis}

Caspase-3 activity and mitochondrial membrane potential $(\Delta \Psi \mathrm{m})$ analysis were isolated using CaspGLOW ${ }^{\mathrm{TM}}$ Fluorescein Active Caspase-3 Staining
Kit (BioVision co., USA) and mitochondrial membrane potential detection kit (JC-1) (Beyotime Biotechnology Inc., shanghai, China) according to the manufacturer's instructions respectively. Luteolin at concentrations of 20 and $40 \mu \mathrm{M}$ were used as treatment for $72 \mathrm{~h}$. DMSO solution was used as control.

\section{Western blot}

After being treated with luteolin at concentrations of $0,10,20,40 \mu \mathrm{M}$ for $72 \mathrm{~h}$, whole cell proteins were extracted with RIPA lysis buffer and protein concentrations were determined by the standard BCA method (Beyotime Institute of BiotechnologyInc., shanghai, China). Then whole cell proteins $(50 \mu \mathrm{g})$ were separated by SDS-PAGE and transferred onto polyvinylidene difluoride membranes (Millipore Corp., Bedford, MA, USA). Membranes were blocked in TBS containing $0.1 \%$ Tween-20 and 5\% dry milk, and probed with primary antibody overnight at $4^{\circ} \mathrm{C}$. Primary antibody directly against Bim, cPARP, CYT-C, p21, p53 and GAPDH (all form Cell Signaling Technology, USA) were used at a dilution of 1:1000, followed by incubating with HRP-conjugated secondary antibodies for $2 \mathrm{~h}$ at room temperature. Signals were visualized using BeyoECL Plus (Millipore, Billerica, MA, USA) and captured using an Image Quant LAS4000 (Fujifilm, Tokyo, Japan). All the experiments were repeated three times. The protein quantification of the Western blot results was normalized to GAPDH and then compared to the control group.

\section{Xenograft experiments}

Fourteen six-week-old female BALB/C-nu mice with green fluorescent protein marker of human esophageal cancer (EC1-E-GFP) were used in this study to test the therapeutic effects of luteolin in vivo. They were cultured in pathogen-free sterile conditions with continuous access to sterile food and water. For tumorigenicity assays, $5 \times 10^{6} / 100 \mu \mathrm{l}$ EC1-EGFP cells were subcutaneously injected into the upper portion of the right hind limb of BALB/c Nude mice to construct ESCC xenograft models. After tumor grows, the xenograft mouse models were randomly divided into two even groups, control and treatment $(50 \mathrm{mg} / \mathrm{kg}$ luteolin) groups. Mice in the control group were injected with HPBCD and mice in the treatment group were injected with luteolin $(50 \mathrm{mg} / \mathrm{kg})$ to enterocoelia as intervention. Tumors were observed by FluorVivo (INDEC BioSystems, CA, USA) and size was measured using calipers every 3 days. Cervical dislocation was conducted after mice being euthanized by Isoflurane (Abbot Laboratories Ltd., North Chicago, IL) inhalation 18 days after luteolin intervention. At the end of this experiment, tumors were harvested and weighed. The condition of mice was observed every day and the mice were weighed twice a week. 


\section{Statistical analysis}

All statistical analyses were conducted by using the SPSS 19.0 statistical software (IBM, Armonk, New York). Results are expressed as means \pm SD. Twotailed independent-samples Student's t-test was used to determine the difference between two mean values, and two-sided $\mathrm{p}$ values less than 0.05 were considered statistically significant.

\section{ACKNOWLEDGMENTS}

This study was supported by Program from New Century Excellent Talents in University, Ministry of Education, China (NCET-11-0949) and a Grant for Key Projects from Henan Province Office of Education, China (14A310005), and partly supported by National Natural Science Foundation, China(U1604189).

\section{CONFLICTS OF INTEREST}

The authors declare that there is no conflicts of interest.

\section{REFERENCES}

1. Eslick GD. Epidemiology of esophageal cancer. Gastroenterol Clin North Am. 2009; 38:17-25, vii. doi: 10.1016/j.gtc.2009.01.008.

2. Zhang Y. Epidemiology of esophageal cancer. World J Gastroenterol. 2013; 19:5598-606. doi: 10.3748/wjg.v19. i34.5598.

3. Siegel RL, Miller KD, Jemal A. Cancer statistics, 2016. CA Cancer J Clin. 2016; 66:7-30. doi: 10.3322/caac.21332.

4. Napier KJ, Scheerer M, Misra S. Esophageal cancer: A Review of epidemiology, pathogenesis, staging workup and treatment modalities. World J Gastrointest Oncol. 2014; 6:112-20. doi: 10.4251/wjgo.v6.i5.112.

5. Cho SH, Shim HJ, Lee SR, Ahn JS, Yang DH, Kim YK, Nam TK, Lee JJ, Kim HJ, Chung IJ. Concurrent chemoradiotherapy with S-1 and cisplatin in advanced esophageal cancer. Dis Esophagus. 2008; 21:697-703. doi: 10.1111/j.1442-2050.2008.00837.x.

6. Higuchi K, Koizumi W, Tanabe S, Sasaki T, Katada C, Azuma M, Nakatani K, Ishido K, Naruke A, Ryu T. Current management of esophageal squamous-cell carcinoma in Japan and other countries. Gastrointest Cancer Res. 2009; 3:153-61.

7. Nakajima M, Kato H. Treatment options for esophageal squamous cell carcinoma. Expert Opin Pharmacother. 2013; 14:1345-54. doi: 10.1517/14656566.2013.801454.

8. Chang H, Shin SK, Cho BC, Lee CG, Kim CB, Kim DJ, Lee JG, Hur J, Lee CY, Bae MK, Kim HR, Lee SK, Park JC, et al. A prospective phase II trial of S-1 and cisplatin-based chemoradiotherapy for locoregionally advanced esophageal cancer. Cancer Chemother Pharmacol. 2014; 73:665-71. doi: 10.1007/s00280-013-2371-y.

9. Wu B, Zhang Q, Shen W, Zhu J. Anti-proliferative and chemosensitizing effects of luteolin on human gastric cancer AGS cell line. Mol Cell Biochem. 2008; 313:12532. doi: 10.1007/s11010-008-9749-x.

10. Ko WG, Kang TH, Lee SJ, Kim YC, Lee BH. Effects of luteolin on the inhibition of proliferation and induction of apoptosis in human myeloid leukaemia cells. Phytother Res. 2002; 16:295-8. doi: 10.1002/ptr.871.

11. Lin Y, Shi R, Wang X, Shen HM. Luteolin, a flavonoid with potential for cancer prevention and therapy. Curr Cancer Drug Targets. 2008; 8:634-46. doi: https://doi. org/10.2174/156800908786241050.

12. Yee SB, Lee JH, Chung HY, Im KS, Bae SJ, Choi JS, Kim ND. Inhibitory effects of luteolin isolated from Ixeris sonchifolia Hance on the proliferation of HepG2 human hepatocellular carcinoma cells. Arch Pharm Res. 2003; 26:151-6.

13. Johnson JL, Gonzalez de Mejia E. Interactions between dietary flavonoids apigenin or luteolin and chemotherapeutic drugs to potentiate anti-proliferative effect on human pancreatic cancer cells, in vitro. Food Chem Toxicol. 2013; 60:83-91. doi: 10.1016/j.fet.2013.07.036.

14. Fang J, Zhou Q, Shi XL, Jiang BH. Luteolin inhibits insulin-like growth factor 1 receptor signaling in prostate cancer cells. Carcinogenesis. 2007; 28:713-23. doi: 10.1093/carcin/bgl189.

15. Zi X, Feyes DK, Agarwal R. Anticarcinogenic effect of a flavonoid antioxidant, silymarin, in human breast cancer cells MDA-MB 468: induction of G1 arrest through an increase in $\mathrm{Cip} 1 / \mathrm{p} 21$ concomitant with a decrease in kinase activity of cyclin-dependent kinases and associated cyclins. Clin Cancer Res. 1998; 4:1055-64.

16. Lindenmeyer F, Li H, Menashi S, Soria C, Lu H. Apigenin acts on the tumor cell invasion process and regulates protease production. Nutr Cancer. 2001; 39:139-47. doi: $10.1207 /$ S15327914nc391_19.

17. Zhang Q, Zhao XH, Wang ZJ. Flavones and flavonols exert cytotoxic effects on a human oesophageal adenocarcinoma cell line (OE33) by causing G2/M arrest and inducing apoptosis. Food Chem Toxicol. 2008; 46:2042-53. doi: 10.1016/j.fct.2008.01.049.

18. Zhang Q, Zhao XH, Wang ZJ. Cytotoxicity of flavones and flavonols to a human esophageal squamous cell carcinoma cell line (KYSE-510) by induction of G(2)/M arrest and apoptosis. Toxicol Vitro. 2009; 23:797-807. doi: 10.1016/j. tiv.2009.04.007.

19. Wang TT, Wang SK, Huang GL, Sun GJ. Luteolin inducedgrowth inhibition and apoptosis of human esophageal squamous carcinoma cell line Eca109 cells in vitro. Asian Pac J Cancer Prev. 2012; 13:5455-61. doi: 10.7314/ APJCP.2012.13.11.5455. 
20. Ju W, Wang X, Shi H, Chen W, Belinsky SA, Lin Y. A critical role of luteolin-induced reactive oxygen species in blockage of tumor necrosis factor-activated nuclear factor-kappaB pathway and sensitization of apoptosis in lung cancer cells. Mol Pharmacol. 2007; 71:1381-8. doi: 10.1124/mol.106.032185.

21. Yamashita N, Kawanishi S. Distinct mechanisms of DNA damage in apoptosis induced by quercetin and luteolin. Free Radic Res. 2000; 33:623-33.

22. Rao PS, Satelli A, Moridani M, Jenkins M, Rao US. Luteolin induces apoptosis in multidrug resistant cancer cells without affecting the drug transporter function: Involvement of cell line-specific apoptotic mechanisms. Int J Cancer. 2012; 130:2703-14. doi: 10.1002/ijc.26308.

23. Cai Q, Rahn RO, Zhang R. Dietary flavonoids, quercetin, luteolin and genistein, reduce oxidative DNA damage and lipid peroxidation and quench free radicals. Cancer Lett. 1997; 119:99-107. doi: 10.1016/S0304-3835(97)00261-9.

24. Ardalan B, Spector SA, Livingstone AS, Franceschi D, Mezentsev D, Lima M, Bowen-Wells CP, Sparling L, Avisar E, Sapp M. Neoadjuvant, surgery and adjuvant chemotherapy without radiation for esophageal cancer. Jpn J Clin Oncol. 2007; 37:590-6. doi: 10.1093/jjco/hym076.

25. Almhanna K, Shridhar R, Meredith KL. Neoadjuvant or adjuvant therapy for resectable esophageal cancer: is there a standard of care. Cancer Control. 2013; 20:89-96.

26. Chung H-S. Cytotoxic triterpenoids on human cancer cell lines from Ixeris sonchifolia. Food Sci Biotechnol. 2000; 9:364-7.

27. Chung HS. Guaianolide Sesquiterpene Lactone from Ixeris sonchifolia Hance with Cytotoxicity in Cultured Human Stomach and Colon Cancer Cell Lines. Food Sci Biotechnol. 2001; 10:433-6.

28. Bog YS, Hwa LJ, Young CH, Ja BS, Soo CJ, Deuk KN. Inhibitory effects of luteolin isolated fromixeris sonchifolia hance on the proliferation of hepg2 human hepatocellular carcinoma cells. Arch Pharm Res. 2003; 26:151-6. doi: 10.1007/BF02976662.

29. Casagrande F, Darbon JM. Effects of structurally related flavonoids on cell cycle progression of human melanoma cells: regulation of cyclin-dependent kinases CDK2 and CDK1. Biochem Pharmacol. 2001; 61:1205-15. doi: 10.1016/S0006-2952(01)00583-4.

30. Matsukawa Y, Marui N, Sakai T, Satomi Y, Yoshida M, Matsumoto K, Nishino H, Aoike A. Genistein arrests cell cycle progression at G2-M. Cancer Res. 1993; 53:1328-31.

31. Chang J, Hsu Y, Kuo P, Kuo Y, Chiang L, Lin C. Increase of Bax/Bcl-X L ratio and arrest of cell cycle by luteolin in immortalized human hepatoma cell line. Life Sci. 2005; 76:1883-93. doi: 10.1016/j.lfs.2004.11.003.

32. Haddad AQ, Venkateswaran V, Viswanathan L, Teahan SJ, Fleshner NE, Klotz LH. Novel antiproliferative flavonoids induce cell cycle arrest in human prostate cancer cell lines.
Prostate Cancer Prostatic Dis. 2006; 9:68-76. doi: 10.1038/ sj.pcan.4500845.

33. Yang SF, Yang WE, Chang HR, Chu SC, Hsieh YS. Luteolin induces apoptosis in oral squamous cancer cells. J Dent Res. 2008; 87:401-6.

34. Zhao Y, Yang G, Ren D, Zhang X, Yin Q, Sun X. Luteolin suppresses growth and migration of human lung cancer cells. Mol Biol Rep. 2011; 38:1115-9. doi: 10.1007/ s11033-010-0208-x.

35. Aneknan P, Kukongviriyapan V, Prawan A, Kongpetch S, Sripa B, Senggunprai L. Luteolin arrests cell cycling, induces apoptosis and inhibits the JAK/STAT3 pathway in human cholangiocarcinoma cells. Asian Pac J Cancer Prev. 2013; 15:5071-6. doi: 10.7314/APJCP.2014.15.12.5071.

36. Park S-H, Ham S, Kwon TH, Kim MS, Lee DH, Kang J-W, Oh S-R, Yoon D-Y. Luteolin induces cell cycle arrest and apoptosis through extrinsic and intrinsic signaling pathways in MCF-7 breast cancer cells. J Environ Pathol Toxicol Oncol. 2014; 33. doi: 10.1615/JEnvironPatholToxicolOn col.2014010923.

37. Selvi RB, Swaminathan A, Chatterjee S, Shanmugam MK, Li F, Ramakrishnan GB, Siveen KS, Chinnathambi A, Zayed ME, Alharbi SA, Basha J, Bhat A, Vasudevan $\mathrm{M}$, et al. Inhibition of p300 lysine acetyltransferase activity by luteolin reduces tumor growth in head and neck squamous cell carcinoma (HNSCC) xenograft mouse model. Oncotarget. 2015; 6:43806-18. doi: 10.18632/ oncotarget.6245.

38. Lim DY, Jeong Y, Tyner AL, Park JH. Induction of cell cycle arrest and apoptosis in HT-29 human colon cancer cells by the dietary compound luteolin. Am J Physiol Gastrointest Liver Physiol. 2007; 292: G66-75. doi: 10.1152/ajpgi.00248.2006.

39. Ong CS, Zhou J, Ong CN, Shen HM. Luteolin induces G1 arrest in human nasopharyngeal carcinoma cells via the Akt-GSK-3beta-Cyclin D1 pathway. Cancer Lett. 2010; 298:167-75. doi: 10.1016/j.canlet.2010.07.001.

40. Wang T-T, Wang S-K, Huang G-L, Sun G-J. Luteolin induced-growth inhibition and apoptosis of human esophageal squamous carcinoma cell line Eca109 cells in vitro. Asian Pacific Journal of Cancer Prevention. 2012; 13:5455-61.

41. Frescas D, Pagano M. Deregulated proteolysis by the F-box proteins SKP2 and $\beta$-TrCP: tipping the scales of cancer. Nat Rev Cancer. 2008; 8:438-49. doi: 10.1038/nrc2396.

42. Choi YH, Zhang L, Lee W, Park K. Genistein-induced $\mathrm{G} 2 / \mathrm{M}$ arrest is associated with the inhibition of cyclin B1 and the induction of p21 in human breast carcinoma cells. Int J Oncol. 1998; 13:391-6. doi: 10.3892/ijo.13.2.391.

43. Davis JN, Singh B, Bhuiyan M, Sarkar FH. Genistein-induced upregulation of p21 WAF1, downregulation of cyclin B, and induction of apoptosis in prostate cancer cells. Nutr Cancer. 1998; 32:123-31. doi: 10.1080/01635589809514730. 
44. Lian F, Bhuiyan M, Li YW, Wall N, Kraut M, Sarkar FH. Genistein-induced G2-m arrest, P21WAF1 upregulation, and apoptosis in a non-small-cell lung cancer cell line. Nutr Cancer. 1998; 31:184-91. doi: 10.1080/01635589809514701.

45. Shao ZM, Alpaugh ML, Fontana JA, Barsky SH. Genistein inhibits proliferation similarly in estrogen receptorpositive and negative human breast carcinoma cell lines characterized by P21WAF1/CIP1 induction, G2/M arrest, and apoptosis. J Cell Biochem. 1998; 69:44-54. doi: 10.1002/(SICI)1097-4644(19980401)69:1<44::AIDJCB5>3.0.CO;2-V.

46. Choi JA, Kim JY, Lee JY, Kang CM, Kwon HJ, Yoo YD, kim TW, Lee YS, Lee SJ. Induction of cell cycle arrest and apoptosis in human breast cancer cells by quercetin. Int J Oncol. 2001; 19:837-44. doi: 10.3892/ijo.19.4.837.

47. Kuo H-M, Chang L-S, Lin Y-L, Lu H-F, Yang J-S, Lee J-H, Chung J-G. Morin inhibits the growth of human leukemia HL-60 cells via cell cycle arrest and induction of apoptosis through mitochondria dependent pathway. Anticancer Res. 2007; 27:395-405.

48. Takagaki N, Sowa Y, Oki T, Nakanishi R, Yogosawa S, Sakai T. Apigenin induces cell cycle arrest and p21/WAF1 expression in a p53-independent pathway. Int $\mathrm{J}$ Oncol. 2005; 26:185-9. doi: 10.3892/ijo.26.1.185.

49. Kobayashi T, Nakata T, Kuzumaki T. Effect of flavonoids on cell cycle progression in prostate cancer cells. Cancer Lett. 2002; 176:17-23. doi: 10.1016/S0304-3835(01)00738-8.

50. Das S, Das J, Samadder A, Paul A, Khuda-Bukhsh AR. Efficacy of PLGA-loaded apigenin nanoparticles in Benzo[a]pyrene and ultraviolet-B induced skin cancer of mice: mitochondria mediated apoptotic signalling cascades.
Food Chem Toxicol. 2013; 62:670-80. doi: 10.1016/j. fct.2013.09.037.

51. Qin R, Shen H, Cao Y, Fang Y, Li H, Chen Q, Xu W. Tetrandrine induces mitochondria-mediated apoptosis in human gastric cancer BGC-823 cells. PLoS One. 2013; 8: e76486. doi: 10.1371/journal.pone.0076486.

52. Chian S, Thapa R, Chi Z, Wang XJ, Tang X. Luteolin inhibits the Nrf2 signaling pathway and tumor growth in vivo. Biochem Biophys Res Commun. 2014; 447:602-8. doi: 10.1016/j.bbrc.2014.04.039.

53. Majumdar D, Jung KH, Zhang H, Nannapaneni S, Wang X, Amin AR, Chen Z, Chen ZG, Shin DM. Luteolin nanoparticle in chemoprevention: in vitro and in vivo anticancer activity. Cancer Prev Res (Phila). 2014; 7:65-73. doi: 10.1158/1940-6207.CAPR-13-0230.

54. Sun DW, Zhang HD, Mao L, Mao CF, Chen W, Cui M, Ma $\mathrm{R}$, Cao HX, Jing CW, Wang Z, Wu JZ, Tang JH. Luteolin Inhibits Breast Cancer Development and Progression In Vitro and In Vivo by Suppressing Notch Signaling and Regulating MiRNAs. Cell Physiol Biochem. 2015; 37:1693-711. doi: 10.1159/000438535.

55. Yang JA, Li JQ, Shao LM, Yang Q, Liu BH, Wu TF, Wu P, Yi W, Chen QX. Puerarin inhibits proliferation and induces apoptosis in human glioblastoma cell lines. Int J Clin Exp Med. 2015; 8:10132-42.

56. Zhang J, Wang Y, Li G, Yu H, Xie X. Down-regulation of nicotinamide $\mathrm{N}$-methyltransferase induces apoptosis in human breast cancer cells via the mitochondria-mediated pathway. PLoS One. 2014; 9: e89202. doi: 10.1371/journal. pone. 0089202 . 